\section{Spontaneous Rupture of the Oesophagus}

The following case is the only example of spontaneous rupture of the oesophagus that occurred during the past ten years in 41,258 consecutive medical admissions to the Royal Victoria Infirmary, Newcastle-upon-Tyne. Ridgway and Duncan (1937) found only 35 recorded cases in the world's literature, but since that time descriptions by various authors have raised the total to over 60. Recovery after immediate thoracotomy has been reported by Barrett (1947), Olsen and Clagett (1947), and Scholefield (1949). Recovery in a disease that was previously uniformly fatal has probably provided the stimulus that has produced the increased number of cases recorded in the last decade.

\section{Case Report}

A man aged 66 was admitted to the Royal Victoria Infirmary at 8 p.m. on April 24, 1949, with a diagnosis of left-sided spontaneous pneumothorax. He had been perfectly well until six hours previously, when, following lunch, he felt sick and vomited. Immediately afterwards he had a severe tearing pain in the left chest and became short of breath. The pain persisted in spite of $\frac{1}{2} \mathrm{gr}$. $(32 \mathrm{mg}$.) of morphine, and the dyspnoea increased.

On admission the patient was orthopnoeic, cyanosed, and sweating; he had a pulse of 98 , and a subnormal temperature. The pupils were pin-point and there was surgical emphysema over the suprasternal notch. The physical signs in the chest were those of a large left-sided pneumothorax. The dyspnoea increased until at 10 p.m. removal of air was necessary. While preparations were being made to do this the patient vomited copiously; he was not re-examined until after removal of the air. The chest was tapped in the eighth interspace in the posterior axillary line. The initial intrapleural pressures were +10 and $+6 \mathrm{~cm}$. of water. A litre of air was removed slowly, after which a bubbling noise was heard, and a dark-brown fluid, identical with the vomitus, was seen at the glass adaptor of the pneumothorax apparatus. The needle was withdrawn. The fluid smelled like vomitus and was acid to litmus.

At this point the physical signs were those of a hydropneumothorax, the fluid occupying the lower third of the chest. A diagnosis of rupture of the oesophagus was made. Pending transfer to a chest centre, when the patient's condition allowed, a water-sealed intercostal drain was inserted by $\mathrm{Mr}$. W. G. Ferguson under local analgesia. Penicillin, $2,000,000$ units, was given intramuscularly at once, and $1,000,000$ units every three hours. The stomach was continuously aspirated through a Ryle's tube. After intercostal drainage the patient was more comfortable; but his condition ceteriorated steadily, and he died within twelve hours of admission.

The post-mortem examination was performed by Dr. F. K. Hill. There was surgical emphysema of the neck, and an incision in the eighth intercostal space in the anterior axillary line. The left lung lay collapsed within the pleural cavity, which contained $1,000 \mathrm{ml}$. of dirty dark-grey fluid. This watery fluid contained an occasional undigested pea. When the lung was lifted a hole was seen in the parietal pleura overlying the oesophagus. Surrounding the hole, and attached to the mediastinum by numerous adhesions, was emphysematous lung tissue. The appearances suggested that a bulla $3 \mathrm{~cm}$. in diameter had ruptured into the mediastinum and pleural cavity. Looking through the bulla at the oesophagus, which lay posteriorly and within the wall of the bulla, there was a longitudinal tear $2 \mathrm{~cm}$. in length on the antero-lateral aspect of the oesophagus. This tear lay immediately above the oesophago-cardiac junction. The mediastinum showed surgical emphysema and early mediastinitis. The oesophagus was normal, except for the longitudinal tear immediately above the cardiac sphincter.
There were, however, numerous adhesions between the oesophagus and the mediastinal aspect of the lung. The stomach showed a chronic prepyloric ulcer $1.5 \mathrm{~cm}$. long and $0.5 \mathrm{~cm}$. wide lying transversely on the posterior wall. There was slight pyloric stenosis. Microscopically, no abnormality of the oesophagus was seen either at the tear or elsewhere.

\section{Discussion}

Scholefield (1949) reviews the symptomatology of this condition, and points out that in almost all recorded cases the patient vomits, usually after a heavy meal, and then suffers from a severe tearing pain either over the lower sternum or posteriorly over the lower thoracic or upper lumbar vertebrae. Pleural effusion, unilateral or bilateral, usually follows, and is accompanied by surgical emphysema over the upper part of the sternum and the neck. The pain is predominant, and several authors have commented on the lack of relief provided by morphine, a feature which this patient demonstrated. It is suggested that during the act of vomiting the cricopharyngeus fails to relax, and there is a rapid rise of the intragastric and intra-oesophageal pressures. When this occurs the oesophagus tears at its weakest point, which is at the lower end just above the diaphragm. The remarkable consistency of the pathological findings supports this theory. Most commonly there is a longitudinal tear $1-8 \mathrm{~cm}$. long, usually on the left posterior wall at the lower end of the oesophagus. The right posterior wali may be affected and there have occasionally been bilateral tears. Sometimes the tear may be on the anterior wall.

The above patient is typical in that he had a sudden onset of a severe tearing pain preceded by vomiting and followed by dyspnoea. It is possible that the slight degree of pyloric stenosis was responsible for a greater intragastric pressure than usual during vomiting, but in the absence of a history of dyspepsia or vomiting the pyloric stenosis is unlikely to have played a major part in the catastrophe.

A point of interest is that on admission a pneumothorax only was present, but that after removal of air there was a hydropneumothorax. It is possible that the pressure within the chest was so great that the diaphragm was forced down and the signs of fluid were not apparent. Another possibility is that the oesophagus ruptured into the bulla, which was adherent to the mediastinum. This bulla in turn ruptured into the pleura, with the rapid production of a pneumothorax and a minimal effusion which was not apparent clinically. The pneumothorax pushed the oesophagus so far over that the tear acted as a valve and prevented the escape of gastric contents. On the evidence available either of these explanations is possible. An alternative explanation of a spontaneous pneumothorax from the rupture of a bulla, the oesophagus being torn by adhesions as the mediastinum was pushed over, is not substantiated by the history, the post-mortem findings, or the descriptions of other recorded cases.

My thanks are due to Dr. C. N. Armstrong for permission to publish this case.

T. A. Grimson, M.D., M.R.C.P.,

Medical Registrar, Royal Victoria Infirmary, Newcastle-upon-Tyne.

REFERENCES

Barrett, N. R. (1947). Brit. J. Surg., 35, 216

Olsen, A M and Clagett, O. T. (1947). Postgrad. Med., 2, 417 Ridgway, E. C., and Duncan, G. G. (1937). Bull. Ayer clin. Lab.. 3, 79 .

Scholefieid, J. (1949). British Medical Journal, 1, 348. 